\title{
Assessment of InTRICATE DG PlanNING WITH Practical LoAD MODEls By USING PSO
}

\author{
Aashish Kumar Bohre ${ }^{1}$ Dr. Ganga Agnihotri ${ }^{2}$ Dr. Manisha Dubey ${ }^{3}$ and Dr. Shilpa \\ Kalambe $^{4}$ \\ Electrical Engineering Department ${ }^{1,2,3,4}$ \\ Maulana Azad National Institute of Technology (MANIT), Bhopal, INDIA ${ }^{1,2,3,4}$
}

\begin{abstract}
This paper presents the optimal sizing and placement of DG by assuming practical load models. The particle swarm optimization technique is used to minimize the multi-objective fitness function (MOFF). This MOFF has considered the performance indices such as a voltage difference index, active power loss index and reactive power loss index. Most of the studies have considered the constant load for distribution system planning which may mislead the exact assessment of the system performance. Thus the voltage dependency of load models is found in a highly demanding issue in updating researches. Keeping in view the urgent need of precise and flawless distribution system planning the effect of different load models on the total load, voltage profile, active and reactive power loss has been evaluated and presented in this paper. The efficacy of the proposed method has been executed by implementing it on the 33-bus radial test system.
\end{abstract}

\section{KEYWORDS}

Optimal sizing and placement of DG, Multi-objective fitness function, Indexes, Load models, PSO.

\section{INTRODUCTION}

Distributed Generator (DG) units are broadly outlined as the generating plants serving a customer on-site or providing funding to a distribution network, connected to the power system at the distribution-level voltages. The primary causes for continued development in the insertion of DG are the environmental concerns, insufficiency of energy sources, constraints on building new transmission and distribution protocols, technological improvements in small generators, power electronics, and energy storage devices for transient backup. However, it was discovered that the improper siting or sizing of DG can counter effect the organization. Power system liberation and therefore the shortage of transmission capacities have led to inflated interest in distributed generation sources [9]. Many researchers have worked on the index based multi-objective function to find the optimal location and size of DG such as [1-2]. The particle swarm optimization (PSO) technique has been described in [4,7-8]). Many approaches for optimal allocation and sizing of DG in distribution systems are introduced by $[3,5,6,9]$. The power flow in the system are described by [10]. 
Electrical \& Computer Engineering: An International Journal (ECIJ) Volume 4, Number 2, June 2015

This paper presents the optimal planning of distributed generation (DG) as an active power sources. Also, proposes the optimal location and sizing of DG based on multi-objective optimization with the different objective indices such as Active Power Loss Index (PLI), Reactive Power Loss Index (QLI), Voltage Deviation Index (VDI) with load models. The achieved results show the overall performance of the system has improved with-DG condition.

\section{The Particle Swarm OPTIMIZation Technique}

The Particle Swarm optimization comes under the class of Swarm Intelligence techniques. The particle swarm optimization was suggested in 1995, by Kennedy and Eberhart [7-8]. It's a popular and more effective optimization technique based on the population search. The basic equations of PSO are given as [4-5]:

$$
\begin{gathered}
v_{(t+1)}=w^{*} v_{t}+c_{1} r_{1}\left(\text { pbest } t_{t}-\text { currentposition }\right)+c_{2} r_{2}(\text { gbest } t-\text { currentposition }) \\
x_{(t+1)}=x_{t}+v_{t+1}
\end{gathered}
$$

Where

$\mathrm{N}$ : total size of swarms.

$\mathrm{t}$ : the iteration number.

$\mathrm{w}$ : is the inertia weight.

$\mathrm{r}_{1}, \mathrm{r}_{2}$ : two random numbers between $(0,1)$.

$\mathrm{C}_{1}, \mathrm{C}_{2}$ : the cognitive and social scaling parameters.

\section{The Multi-objective Fitness (MOFF) Function And LoAd MODELS}

The Multi-objective Fitness function (MOFF) is defined by the several system performance index as:

$$
M O F F=w_{1} \times P L I+w_{2} \times Q L I+w_{3} \times V D I
$$

And also, with weight factor value given as:

$$
M O F F=0.45 * \mathrm{PLI}+0.30 * \mathrm{QLI}+0.25 * \mathrm{VDI}
$$

Where, $\sum_{i=1}^{3} w_{i}=1$

The detail to select the weight factor of the indices is given in the references [1-2].

The active power loss index (PLI) is: 


$$
P L I=\frac{P L_{D G}}{P L_{N o-D G}}
$$

The reactive power loss index $(\mathrm{QLI})$ is:

$$
Q L I=\frac{Q L_{D G}}{Q L_{N o-D G}}
$$

The voltage deviation index (VDI) is

$$
V D I=\max _{j=2}^{n}\left(\frac{V_{r e f f}-V_{D G j}}{V_{r e f f}}\right)
$$

The load models for the particular loads can be mathematically expressed as:

$$
\left.\begin{array}{l}
P_{i}=P_{o i} V_{i}^{\alpha} \\
Q_{i}=Q_{o i} V_{i}^{\beta}
\end{array}\right\}
$$

Where, $\mathrm{Pi}$ and $\mathrm{Qi}$ are real and reactive power at bus $\mathrm{i}, \mathrm{P}_{\mathrm{oi}}$ and $\mathrm{Q}_{\mathrm{oi}}$ are the active and reactive operating points at bus $\mathrm{i}, \mathrm{V}_{\mathrm{i}}$ is the voltage at bus $\mathrm{i}$, and $\alpha$ and $\beta$ are active and reactive power exponents. The table-1 gives the load models exponent values [1-2].

Table-1: The exponent values for load models

\begin{tabular}{|c|c|c|}
\hline Load type & $\boldsymbol{\alpha}$ & $\boldsymbol{\beta}$ \\
\hline Constant & 0 & 0 \\
\hline Industrial load & 0.18 & 6 \\
\hline Residential load & 0.92 & 4.04 \\
\hline Commercial load & 1.51 & 3.4 \\
\hline
\end{tabular}

\section{ReSUlts AND Discussions}

Table 2 presents the values of multi objective fitness function obtained for 33 bus system $[6,9]$ using various load models. According to the fitness function the values of optimal location for DG installation with corresponding optimal DG size has been evaluated. The requisite for optimal DG designing is the minimum active as well as reactive power losses evaluation after its installation at respective location. 
Electrical \& Computer Engineering: An International Journal (ECIJ) Volume 4, Number 2, June 2015

\subsection{Impact of Load Models on DG designing Parameters}

Table 2 portrays the influence of using load models on DG designing parameter evaluation. It can be observed that the designing parameters obtained for constant load model shows noticeable variation as compared to other practical load models for the same system data. The optimal location obtained for the system with constant load is bus 6 whereas if the practical load models are assumed the optimal location is bus 7 . Thus the respective variation in other parameters can also be obtained. The optimal size of DG required to be installed at bus 6 is $2.7 \mathrm{MW}$ whereas at bus 7 it is $2.2 \mathrm{MW}$ for industrial load model, 1.4 MW for residential load and 1.1 MW for commercial load. The percentage of active loss reduction indicated for the system with constant load model is $46.92 \%$ and reactive power loss reduction is $39.9 \%$. Whereas for the system with practical load models approximately 55 to $61 \%$ of active loss and 52 to $63 \%$ of reactive power loss reduction can be obtained. This indicates that constant load model assumption may mislead the correct DG designing parameters evaluation.

Table 2. DG designing parameters evaluated for 33 bus system with various load models

\begin{tabular}{|c|c|c|c|c|c|c|c|c|c|}
\hline \multirow{2}{*}{ Load Type } & \multirow{2}{*}{ MOFF } & \multirow{2}{*}{$\begin{array}{c}\text { PDG } \\
(\mathbf{M W})\end{array}$} & $\begin{array}{c}\text { Opti } \\
\text { mal } \\
\text { bus }\end{array}$ & \multicolumn{2}{|c|}{$\begin{array}{c}\text { Loss No-DG } \\
\text { LMW) }\end{array}$} & \multicolumn{2}{|c|}{$\begin{array}{c}\text { Loss With- DG } \\
\text { (MVAR) }\end{array}$} & \multicolumn{2}{l|}{$\%$ loss Reduction } \\
\cline { 5 - 10 } & & & & $\mathbf{P}_{\mathbf{L}}$ & $\mathbf{Q}_{\mathbf{L}}$ & $\mathbf{P}_{\mathbf{L}}$ & $\mathbf{Q}_{\mathbf{L}}$ & $\mathbf{P}_{\mathbf{L}}$ & $\mathbf{Q}_{\mathbf{L}}$ \\
\hline Constant load & 0.3845 & 2.7123 & 6 & 0.211 & 0.1431 & 0.1112 & 0.082 & 46.92 & 39.90 \\
\hline Industrial load & 0.321925 & 2.201644 & 7 & 0.1155 & 0.0781 & 0.0457 & 0.0364 & 60.43 & 53.39 \\
\hline Residential load & 0.4194 & 1.4785 & 7 & 0.0649 & 0.0432 & 0.0251 & 0.0159 & 61.32 & 63.19 \\
\hline Commercial load & 0.4815 & 1.0997 & 7 & 0.0658 & 0.0502 & 0.0291 & 0.0205 & 55.78 & 59.16 \\
\hline
\end{tabular}

\subsection{Impact of load model assumption on Voltage profile correction}

Figures 1 to 4 shows the voltage profile correction obtained after DG of optimal size installed at the evaluated optimal location. The pattern of voltage profile correction is approximately same. What varies is the magnitude of voltages at all buses. A remarkable difference of voltage magnitudes before and after DG installation in the system with constant load model can obtained. Table 3 indicates that the minimum voltage obtained for the system without DG for constant load model is 0.90 and the voltage gradation obtained is up to 0.94 . Whereas for the practical load models the minimum voltage obtained without DG is in the range of 0.93 to 0.96 and the gradation in it obtained after DG installation is up to 0.97 . Thus the voltage profile indication is also affected by respective load model assumption. 
Electrical \& Computer Engineering: An International Journal (ECIJ) Volume 4, Number 2, June 2015

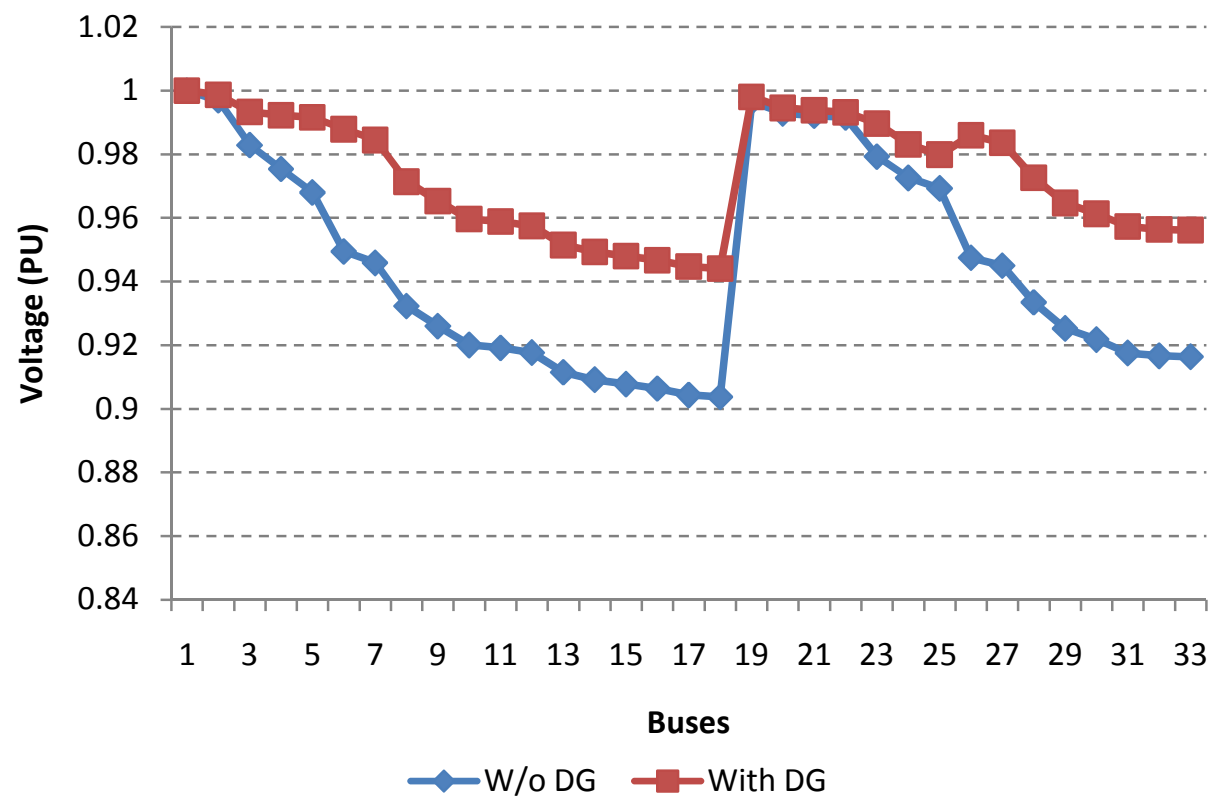

Figure 1. Voltage Profile Improvement of the System with Constant Load Model

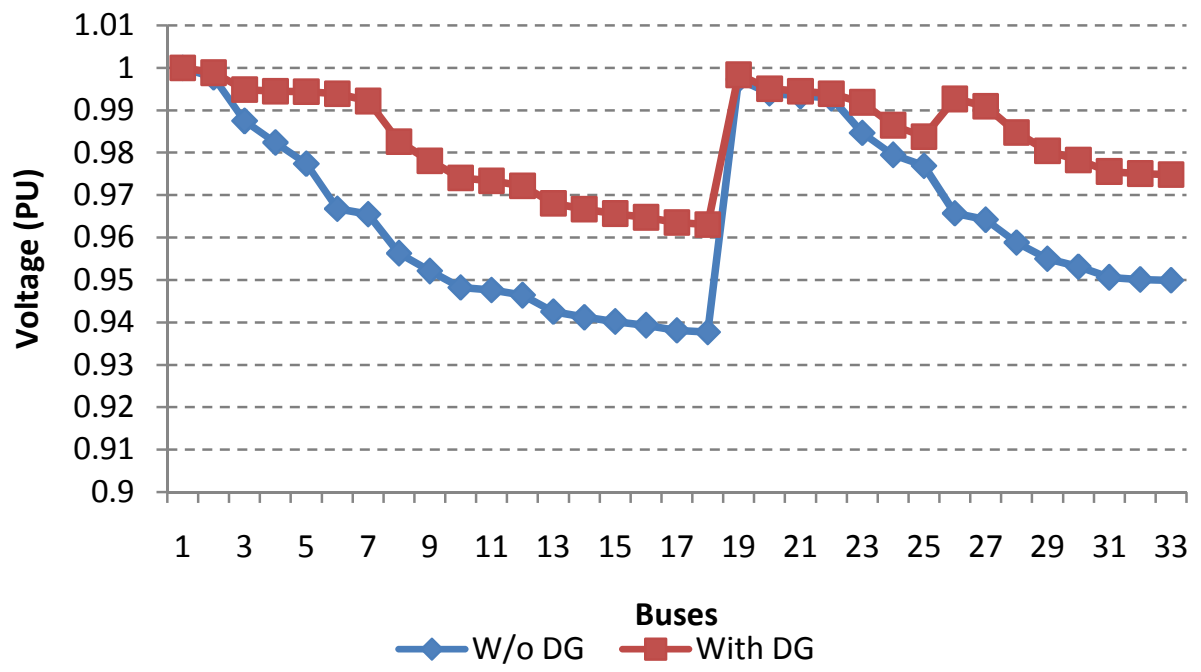

Figure 2. Voltage Profile Improvement of the System with Industrial Load Model 
Electrical \& Computer Engineering: An International Journal (ECIJ) Volume 4, Number 2, June 2015

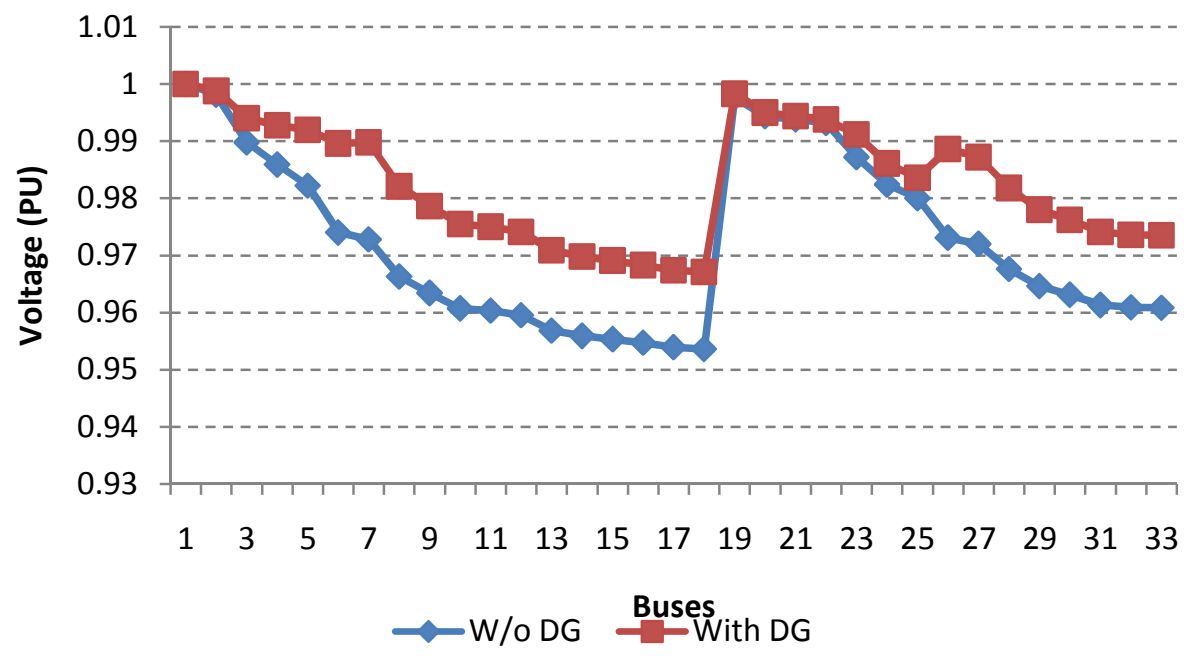

Figure 3. Voltage Profile Improvement of the System with Industrial Load Model

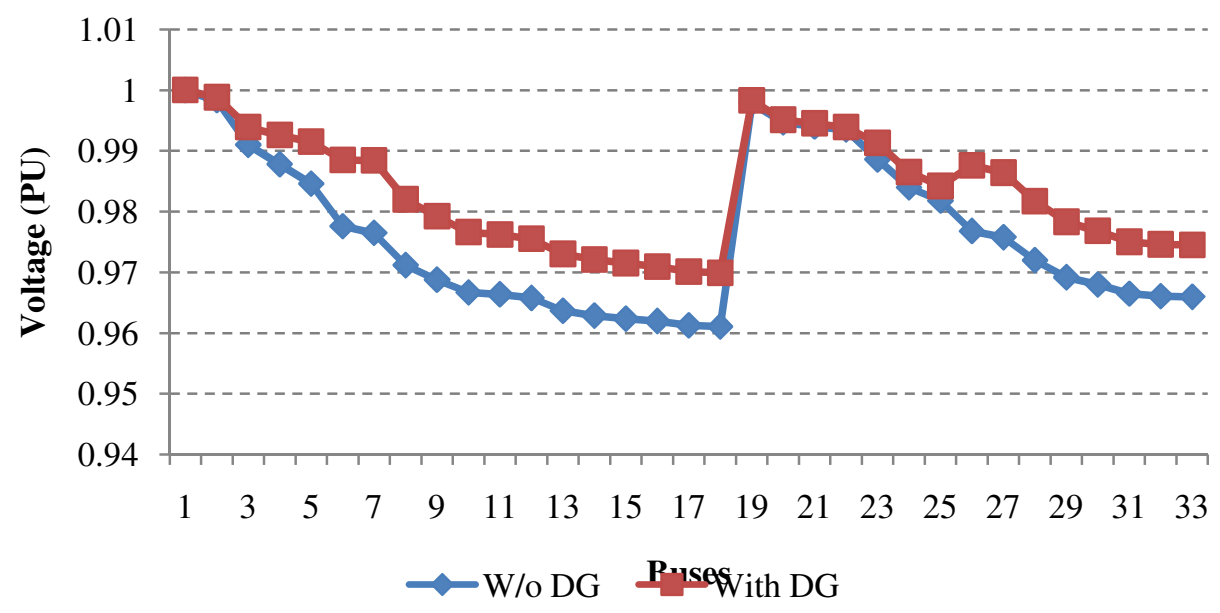

Figure 4. Voltage Profile Improvement of the System with Commercial Load Model

Table 3 Voltage Profile Correction

\begin{tabular}{|c|c|c|c|c|}
\hline Load Models & \multicolumn{2}{|c|}{ Voltage Without DG } & \multicolumn{2}{c|}{ Voltage With DG } \\
\cline { 2 - 5 } & Max & Min & Max & Min \\
\hline Constant & 1 & 0.90 & 1 & 0.94 \\
\hline Industrial & 1 & 0.9377 & 1 & 0.963 \\
\hline Residential & 1 & 0.954 & 1 & 0.967 \\
\hline Commercial & 1 & 0.96 & 1 & 0.97 \\
\hline
\end{tabular}


Electrical \& Computer Engineering: An International Journal (ECIJ) Volume 4, Number 2, June 2015

\section{Conclusions}

In this paper the efficacy of load model's assumption of the appropriate distribution system designing is evaluated. It is shown that the assumption of the constant load model may mislead the correct distribution system planning. Hence to investigate the accurate and reliable planning of DG insertion the effect of load models is mandatory. The evaluated results depict that the size of DG, optimal location, voltage profile of the system and the active and reactive losses of the system vary according to load. It is also observed that the value of voltage profile of the system is improved and the losses are decreased for all load model with-DG as compared to with-out-DG condition of the system.

\section{REFERENCES}

[1] Deependra Singh, Devender Singh, and K. S. Verma, "Multiobjective Optimization for DG Planning With Load Models" IEEE Transactions on Power Systems, February 2009, vol. 24, no. 1, pp. 427436.

[2] A.M. El-Zonkoly, "Optimal placement of multi-distributed generation units including different load models using particle swarm optimization" ELSEVIER, swarm and evolutionary computation, vol.1, 2011, pp. 50-59.

[3] R. Srinivasa Rao, K. Ravindra, K. Satish, and S. V. L. Narasimham, "Power Loss Minimization in Distribution System Using Network Reconfiguration in the Presence of Distributed Generation" IEEE Transactions On Power Systems, VOL. 28, NO. 1, FEBRUARY 2013.

[4] A.K. Bohre, G. Agnihotri, and M. Dubey, "Hybrid butterfly based particle swarm optimization for optimization problems," First International Conference on Networks \& Soft Computing (ICNSC), 2014, pp.172-177, 19-20 Aug. 2014. doi: 10.1109/CNSC.2014.6906650.

[5] A.K. Bohre, G. Agnihotri, M. Dubey, and J. S. Bhadoriya "A novel method to find optimal solution based on modified butterfly particle swarm optimization," International Journal of Soft Computing, Mathematics and Control (IJSCMC), vol. 3, no. 4, pp.1-14, Nov. 2014. doi: 10.14810/ijscmc.2014.3401.

[6] Zhu, J. Z. Optimal reconfiguration of electrical distribution network using the refined genetic algorithm. Electric Power Systems Research, 2002, 62(1), 37-42.

[7] R.C. Eberhart, and J. Kennedy, "A new optimizer using particle swarm theory," Proceedings Sixth International Symposium on Micro Machine and Human Science (Nagoya, Japan), IEEE Service Center, Piscataway, NJ, pp.39-43, 4-6, Oct, 1995. doi: 10.1109/MHS.1995.494215.

[8] J. Kennedy, and R.C. Eberhart, "Particle Swarm Optimization", IEEE International Conference on Neural Networks Proceedings, pp. 1942-1948, vol. 4, Nov. / Dec. 1995. doi: 10.1109/ICNN.1995.488968.

[9] Kalambe, S., Agnihotri, G., \& Bohre, A. K. An Analytical Approach for Multiple Dg Allocation in Distribution System. Elect and Electron Engg: An Inter J (ELELIJ), August, 2013, 2(3), 39-48.

[10] Hadi Sadat, "Power system analyses," TMH Publication, 2002 Edition. 


\section{AUTHORS}

Aashish Kumar Bohre ${ }^{1}$ received B.E. degree in Electrical and Electronics engineering from UIT- RGPV Bhopal, (2009), and M-Tech degree in Power System (2011) from MANIT, Bhopal. At the moment he is Ph.D. scholar at MANIT, Bhopal, India. His research interest includes Distribution system operation and planning, Distributed generation, Power System Optimization, Smart Grid Operation. Email: aashu371984@gmail.com, aashish_bohre@yahoo.co.in

Dr. Ganga Agnihotri ${ }^{2}$ received BE degree in Electrical engineering from MACT, Bhopal (1972), the ME degree (1974) and PhD degree (1989) from University of Roorkee, India. Since 1976 she is with Maulana Azad College of Technology (currently MANIT), Bhopal in various positions. Currently she is professor. Her research interest includes Power System Analysis, Power System Optimization and Distribution Operation. Email: ganga1949@gmail.com

Dr. Manisha Dubey ${ }^{3}$ was born in Jabalpur in India on 15th December 1968. She received her B.E (Electrical), M.Tech. (Power Systems) and Ph.D (Electrical Engg.) in 1990, 1997 and 2006 respectively. She is working as Professor at the Department of Electrical Engineering, Maulana Azad National Institute of Technology, Bhopal, India. Her research interests include power systems, Genetic Algorithms, Fuzzy Logic systems and application of Soft Computing Techniques in power system dynamics and control. Email: manishadubey6@gmail.com

Dr. Shilpa Kalambe ${ }^{4}$ Shilpa Kalambe received BE degree in Electronics \& Power Engg. and M.Tech degree in Integrated Power System From Nagpur University, India. She has completed her Ph.D from MANIT, Bhopal, India. At the moment she is working at MANIT, Bhopal, India. Her research interest includes Power System optimization, Distribution System Planning and Renewable Energy Systems.
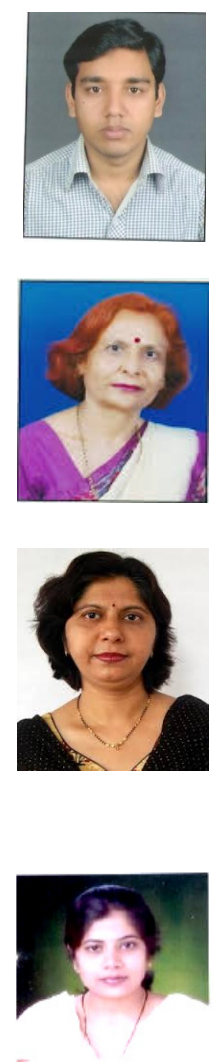